\title{
Cat fit and bull fight: Assessment of aggression in medical students as a prelude to conduct violence in future
}

\author{
Acharya $\mathrm{J}^{1}$, Lama $\mathrm{G}^{2}$, Acharya $\mathrm{J}^{3}$, Manandhar $\mathrm{N}^{4}$, Pant $\mathrm{A}^{5}$ \\ 'Jenash Acharya, Assistant Professor; ${ }^{2}$ Geshu Lama, Lecturer, Department of Forensic Medicine, Kathmandu Medical \\ College Teaching Hospital, Kathmandu, Nepal; ${ }^{3}$ Jemish Acharya, PhD Scholar, Global Health, Mahidol University, Thailand; \\ ${ }^{4}$ Naresh Manandhar, Associate Professor, Department of Community Medicine, Kathmandu Medical College Teaching \\ Hospital, Kathmandu, Nepal; ${ }^{5}$ Abhishek Pant, Nepal Medical Council registered MBBS Graduate, Kathmandu Medical \\ College Teaching Hospital, Kathmandu, Nepal.
}

\begin{abstract}
Background:The intensity of aggression present in any person determines his/her threat to conduct violent and impulsive act against members of the society or else family, friends or foes, which necessitates a crucial analytical instrument for identification of such behaviour in smaller groups of societies.

Objectives: To assess a group of medical students from Kathmandu, Nepal for potential risk they bear to conduct violence in future medical practice.

Methodology: A self-administered pre-validated Bush and Perry Aggression Questionnaire was used in this descriptive cross-sectional study to analyse emotional and cognitive component among 235 medical students of Nepal between February and May 2019. A Likert-type bipolar scale was used for response format ranging from one (extremely uncharacteristic) to five (extremely characteristic). Questionnaire explored four factors: physical aggression, verbal aggression, anger and hostility. Mean scores of aggression were computed and compared with gender and level of education by conducting independent t-test with level of significance at 0.05 .

Results: The mean scores were $20.73 \pm 6.33,13.97 \pm 3.87,18.79 \pm 5.20$ and $20.17 \pm 6.68$, for physical aggression, verbal aggression, anger and hostility respectively. Males had higher score of physical aggression statistically significant at $p<0.05$. The mean Bush and Aggression Perry Questionnaire score was calculated to be $71.66 \pm 15.71$, but insignificant ( $p>0.05$ ) when compared between sexes, and level of education (second semester and seventh semester students). Conclusion: Male medical students were more prone to hostility and physical aggression than female students who were more liable (statistically insignificant) to verbal aggression and anger.
\end{abstract}

Key words: Actuarial assessment; Bush and Perry Aggression Questionnaire; Medical students; Violence.

DOI: https://doi.org/10.3126/jkmc.v8i4.32381

\section{INTRODUCTION}

Amongst diverse variants of anti-social behaviours, aggression is considered to be one of the chief indicators to the risk of violence. Aggression could be persistent or continual behaviour in some individuals with extreme

Address for correspondence

Dr. Jenash Acharya

Assistant Professor, Department of Forensic Medicine

Kathmandu Medical College Teaching Hospital

Sinamangal, Kathmandu, Nepal

E-mail: jenashacharya65@gmail.com

ORCID: https://orcid.org/0000-0002-1452-0483

ORCID: Geshu Lama: https://orcid.org/0000-0002-0801-9270

Jemish Acharya: https://orcid.org/0000-0002-7369-5013

Naresh Manandhar: https://orcid.org/0000-0002-4113-7076

Abhishek Pant: https://orcid.org/0000-0002-5583-9546 behaviour problems whereas among wide-range of individuals this component is more or less situational or temporary. Anger as one of the components of aggression has been correlated as a link between aggression and hostility'.

An assessment for intensity of aggression present in any person determines his/her threat to conduct violent and impulsive act against members of the society or else family, friends or foes. This necessitates a crucial analytical instrument for identification of such behaviour in smaller groups of societies, which in our study are group of medical students.

Noteworthy progress has transpired with time to analyze behavioral problems and their correlate among various 
groups of individuals ${ }^{2,3}$. These analyses were carried out in the form of inventories, interviews, checklists and questionnaires; formats which have modified with time owing to academic developments in the field of behavioral sciences ${ }^{4,5}$.Validation and accuracy of these tools are linked to components of risk of violence, most of which are based on lengthy interviews and complex interpretations. An alternative method of assessment which has evolved with time is by scoring in a scale of inventories; the actuarial assessment method (AAM) ${ }^{6}$.

Through this article, an attempt is made to analyze components associated with aggressive behavior using AAM in adolescent to adult group of medical students of Nepal aged 18-25 years, using Bush and Perry Aggression Questionnaire' ${ }^{1}$. Four factors - physical aggression, verbal aggression, anger and hostility as postulated by Bush and Perry underwent an actuarial analysis to assess risk of violence among male and female medical students in future using series of questions under each factor ${ }^{1,4}$.

\section{METHODOLOGY}

The self-administered pre-validated questionnaire used in this descriptive cross-sectional study, designed as Bush and Perry Aggression Questionnaire (BPAQ), was intended to analyze emotional and cognitive component ${ }^{1}$ among adolescents to adult medical students of Kathmandu, Nepal. The study was conducted from $2^{\text {nd }}$ February 2019 to $4^{\text {th }}$ May 2019. A Likert-type bipolar scaling method for response format was used, which ranged from one (extremely uncharacteristic of subject) to five (extremely characteristic of subject). The questionnaire explored four factors: physical aggression (nine items), verbal aggression (five items), anger (seven items) and hostility (eight items). The maximum achievable score by a subject on the BPAQ is 145 viz. physical aggression-45, verbal aggression25 , anger aggression- 35 and hostility aggression- 40 . A non-probability sampling incorporated 235 medical students from one among five medical institutions within Kathmandu valley. From among the five medical colleges in Kathmandu valley, one was chosen purposively. From a total of approximately 490 students enrolled in MBBS curriculum in the college, $40 \%$ were enrolled in the study once the selection criteria were met. An additional $20 \%$ was added to cover withdrawal issues and a minimum sample size of 235 was estimated. Following ethical clearance from Institutional Review Committee, Kathmandu Medical College, self-reported data was subjected to response bias by implementation of compliance by means of informed expressed consent.
Age, gender, level of education was assessed against risk of violence in future, which was derived using a valid questionnaire assessing physical, verbal aggression, anger and hostility. Data was entered and analyzed using Statistical Package for the Social Sciences (SPSS version 17.0). Descriptive statistics were calculated for mean and standard deviation. Mean scores of aggressions were computed and compared with age, gender and level of education by conducting independent t-test with level of significance at 0.05 .

\section{RESULTS}

Among the total respondents (235), there were $51.5 \%$ males and $48.5 \%$ females. The mean age of the respondents was 21.52 years (minimum 18 years, maximum 25 years). From a total of nine questions on physical aggression, $51.5 \%$ answered that it was extremely uncharacteristic of them to be unable to "control the urge to strike another person", whereas 25\% reported that it was extremely characteristic of them to "resort to violence to protect my rights". In context to verbal aggression, it was reported to be extremely uncharacteristic of $18.3 \%$ of respondents to get into arguments when people disagreed with them. From the total respondents, in response to query about anger, around $35 \%$ reported that it was extremely characteristic of them to "flare up quickly but get over it quickly". In context to hostility, $15.3 \%$ reported that it was extremely characteristic of them to "sometimes feel that people are laughing at me behind my back".

The mean scores were 20.73 \pm 6.33 for physical aggression, $13.97 \pm 3.87$ for verbal aggression, 18.79 \pm 5.20 for anger and $20.17 \pm 6.68$ for hostility. When compared with gender it was seen that males had a higher score of physical aggression than females which was statistically significant at $p<0.05$. However, females showed higher mean scores in verbal aggression, anger and hostility when compared to males. But these findings were not statistically significant (Table 1).

The 95\% confidence interval of the difference between lower and upper bounds were 1.08 and 4.27 for physical aggression, -1.09 and 0.90 for verbal aggression, -2.32 and -0.34 for anger and -3.80 and -0.40 for hostility.

The mean BPAQ score was calculated to be $71.66 \pm$ 15.71 among total respondents (minimum 37 points, maximum 73.66 points) but showed insignificant $p$-value $(p>0.05)$ when mean BPAQ scores were compared between males and females (Table 2). The mean BPAQ scores when compared between the semesters 
Table 1: Comparison of scores by gender

\begin{tabular}{|c|c|c|c|c|c|c|}
\hline Variable & Gender & $\mathbf{N}$ & Mean & SD & SEM & p-value \\
\hline \multirow{2}{*}{ Physical aggression } & Male & 121 & 22.03 & 5.55 & .50 & \multirow{2}{*}{0.001} \\
\hline & Female & 114 & 19.35 & 6.82 & .63 & \\
\hline \multirow{2}{*}{ Verbal aggression } & Male & 121 & 13.92 & 3.98 & .36 & \multirow{2}{*}{0.85} \\
\hline & Female & 114 & 14.01 & 3.77 & .35 & \\
\hline \multirow{2}{*}{ Anger } & Male & 121 & 18.31 & 5.01 & .45 & \multirow{2}{*}{0.14} \\
\hline & Female & 114 & 19.30 & 5.38 & .50 & \\
\hline \multirow{2}{*}{ Hostility } & Male & 121 & 19.14 & 6.56 & .59 & \multirow{2}{*}{0.01} \\
\hline & Female & 114 & 21.25 & 6.66 & .62 & \\
\hline
\end{tabular}

*p-value from t-test/significance at 0.05; SD: Standard Deviation, SEM: Standard Error of Mean

Table 2: BPAQ score by gender

\begin{tabular}{ccccccc} 
Variable & Gender & N & Mean & SD & SEM & p-value \\
BPAQ & Male & 121 & 73.42 & 14.44 & 1.31 & 0.80 \\
Score & Female & 114 & 73.92 & 17.01 & 1.59 & \\
\hline
\end{tabular}

*p-value from t-test/significance at 0.05; SD: Standard Deviation, SEM: Standard Error of Mean

that the students were enrolled in (second semester $73.66 \pm 14.33$ and seventh semester 73.66 \pm 17.52), the difference in means was not statistically significant as well ( $p$-value>0.05).

\section{DISCUSSION AND CONCLUSION}

Violence is characterised by behaviour intending to cause physical or psychological harm to a person's body, mind, reputation or property, instigated by one's aggressive behaviour. This behaviour can be hostile when the act is impulsive and prompted with rage. Assessment of aggression can thus help identify a person's chances of conducting violence to society when $\mathrm{s} / \mathrm{he}$ is under influence of stress and anger.Hostility is a continuous cognitive emotion in human resulting from a negative appraisal which is expressed through anger. Anger is a transitory feeling triggered by specific conditional activities of the brain. Moreover, hostility is a prolonged negative expression of anger resulting from negative appraisals $s^{7,8}$. Both anger and hostility are forms of aggression, either verbal or physical.

At present, trending scientific approaches being practiced by researchers to assess risk of violence are the Actuarial Approach Model and Structural Professional Judgment Model (SPJ). Both of these approaches are similar in the sense that pre-determined risk factors demonstrated systematically in past researches are reanalyzed among different subject groups ${ }^{9,10}$. The vital difference in these two approaches lies in the decision or judgment by the evaluator. Fixed algorithms and scores are calculated for AAM numerically to focus on prediction, whereas in SPJ approach, personal expertise and aptitude to interpret the facts provided by subjects through structured assessment are rated by professionals with empirical knowledge, moreover, focusing on invention or rediscovery in clinical/diagnostic set-up rather than in prediction of risk for violence in a given community ${ }^{11,12}$.

Although SPJ method was initially considered the better method for risk assessment researches among adults and adolescents ${ }^{13,14}$, evenhanded data verifications congregated over time have shown that AAM is functional in determining people at high risk of repetition of aggressive behavior even after facing retribution of the previous such act, in other words; recidivism to aggressive $\mathrm{act}^{15-17}$. With rising concern related to violence against and/or by the doctors in Nepal, an attempt was made through this study to analyze if the trait of aggression is possessed by the doctor during his early career as a student. The AAM method hence justified as a tool in this study to reckon risk of violence among medical students in future.

Neurobiological allusion of emotional regulations susceptible for violence and impulsive acts are believed to be facilitated due functional or structural anomalies in an inter-connected neural meshwork comprising of amygdala, areas of prefrontal cortex, hypothalamus, anterior mid cingulated cortex, pre-optic region, insular cortex and ventral striatum ${ }^{18}$. A study done on Japanese population by Seishu Nakagawa et al using a magnetic resonance imaging in hostile behavior subscale proposed association of hostility with gray matter density; moreover, the anterior mid-cingulated 
cortex was concluded to be vital for cognitive aspects of hostility ${ }^{19}$. The sex differences for hostility in their study showed male to be more inclined towards hostility than females, a finding as similar to our study ( $p$-value $=0.01$ ).

Lesch KP and Merschdorf $U$ outlined the classical neurotransmitters associated with aggression. Impulsive acts and aggressive behaviour were correlated with cerebrospinal fluid concentration of a serotonin metabolite $5-\mathrm{HT}$ which provided a convincing relation ${ }^{20}$. Androgens, oestrogens and post pubertal testosterones are few mediators among many more that interact with the serotonin $5-\mathrm{HT}$ receptors to facilitate aggression through a pathway; too complex for detailed understanding of aggression at a molecular level ${ }^{21}$.

Although the mechanism of causation of aggression has been explored to a molecular level, the actual reason as to why psychometric analyses done in cross cultural settings globally produce similar kind of results when compared with male and female sexes is an appealing matter for further study with larger sample size and multi-disciplinary approach including psycho-social, molecular and genetic analysis. Almost all studies referred over period of time from at different parts of world have produced similar kind of results that males are more prone to hostility and physical aggression than females and that females are less but significant and liable to verbal aggression and anger ${ }^{22-25}$.The result from our analysis among male and female medical students was no exception to this (significant for physical aggression in males at $p<0.05$ ).

The increasing number of violence against medical personnel as reflected in press and medical anecdotes has emerged as a disorderly menace in and around Indian sub-continent 26-28. Factors associated for violent activities within healthcare facility can broadly be identified due to three major factors: the patient factor, the facility/environment and the medical professional's factor. Gross examples of speculations behind such medico-legal acts have been outlined due to long working hours, time deficit for examination of outnumbered patient in a given time frame resulting in poor doctor patient communication, unrestricted entry of patient's/visitors under influence of drugs/alcohol, lack of protocols for preparedness in such circumstances, inability to identify individuals prone to conduct such act within hospital premises and apathy in government policy to handle such cases, to name a few ${ }^{29,30}$.

This study is a probe into the doctor factor; a psychosocial trait for risk of violence that a future doctor may possess during his adolescence which possibly could determine his aggressive behaviour later in his career; hence resulting in a breach in communication between healthy doctor-patient relationships. Certain level of mindfulness based interventions in such adolescent medical students may be effective in reducing aggression through emotional regulations. Case controlled studies on effect of such mindfulness measures including effects of meditations, yoga, dialectical behaviour and commitment therapy on aggression and violence have proved that such interventions play vital role in reducing unanticipated outcomes during healthcare procedures $^{31}$. Authors also suggests, further such studies be conducted in more objective methods that provide a multifaceted understanding of aggression among not only medical students but fresh medical graduates.

\section{REFERENCES}

1. Buss A, Perry M. The Aggression Questionnaire. J PersSoc Psychol. 1992;63(3):452-9. [DOI]

2. Harris GT, Rice ME, Quinsey VL. Violent recidivism of mentally disordered offenders: The development of a statistical prediction instrument. Crim Justice Behav. 1993 Dec;20(4):315-35.[DOI]

3. Webster CD, Douglas KS, Eaves D, Hart SD. Assessing risk of violence to others. Impulsivity: Theory, assessment, and treatment. 1997 Jun 20:251-77.

4. Buss $A H$, Durkee $A$. An inventory for assessing different kinds of hostility. J Consult Psychol. 1957 Aug;21(4):343.[DOI]

5. Baer RA, Wetter MW, Berry DT. Effects of information about validity scales on underreporting

of symptoms on the MMPI-2: An analogue investigation. Assessment. 1995 Jun;2(2):189-200. [DOI]

6. Diamond PM, Magaletta PR. The short-form BussPerry Aggression questionnaire (BPAQ-SF) a validation study with federal offenders. Assessment. 2006 Sep;13(3):227-40.[DOI]

7. Jackson GE. The problem of hostility psychologically and theologically considered. J Relig Health. 1972 Jan 1;11(1):73-93. [DOI]

8. Tyson PD. Physiological arousal, reactive aggression, and the induction of an incompatible relaxation response. Aggress Violent Behav. 1998 Jun 1;3(2):143-58. [DOI] 
9. Nicholls TL, Ogloff JR, Douglas KS. Assessing risk for violence among male and female civil psychiatric patients: the HCR-20, PCL: SV, and VSC. Behav Sci Law. 2004 Jan;22(1):127-58. [DOI]

10. Doyle M, Dolan M, McGovern J. The validity of North American risk assessment tools in predicting inpatient violent behaviour in England. Legal Criminol Psychol. 2002 Sep;7(2):141-54. [DOI]

11. Otto RK. Assessing and managing violence risk in outpatient settings. J Clin Psychol. 2000 Oct;56(10):1239-62. [DOI]

12. Lodewijks HP, Doreleijers TA, De Ruiter C, Borum R. Predictive validity of the Structured Assessment of Violence Risk in Youth (SAVRY) during residential treatment. Int J Law Psychiatry. 2008 Jun 1;31(3):263-71. [DOI]

13. De Vogel V, De Ruiter C. Structured professional judgment of violence risk in forensic clinical practice: A prospective study into the predictive validity of the Dutch HCR-20. Psychol Crime Law. 2006 Jun 1;12(3):321-36. [DOI]

14. Borum R, Lodewijks $H$, Bartel PA, Forth AE. Structured assessment of violence risk in youth (SAVRY). In: Handbook of violence risk assessment. Routledge; 2011 Apr 27. p.73-90.

15. Quinsey VL, Harris GT, Rice ME, Cormier CA. Violent offenders: Appraising and managing risk. American Psychological Association. 2006. [DOI]

16. Harris GT, Rice ME, Camilleri JA. Applying a forensic actuarial assessment (the Violence Risk Appraisal Guide) to non-forensic patients. J Interpers Violence. 2004 Sep;19(9):1063-74. [DOI]

17. Monahan J, Steadman HJ, Robbins PC, Appelbaum P, Banks S, Grisso T, Heilbrun K, Mulvey EP, Roth $\mathrm{L}$, Silver E. An actuarial model of violence risk assessment for persons with mental disorders. Psychiatr Serv. 2005 Jul;56(7):810-5. [DOI]

18. Davidson RJ, Putnam KM, Larson CL. Dysfunction in the neural circuitry of emotion regulation- $A$ possible prelude to violence. Science. $2000 \mathrm{Jul}$ 28;289(5479):591-4. [DOI]

19. Nakagawa $S$, Takeuchi $H$, Taki $Y$, Nouchi R, Sekiguchi A, Kotozaki Y, Miyauchi CM, lizuka K, Yokoyama R,
Shinada T, Yamamoto Y. The anterior midcingulate cortex as a neural node underlying hostility in young adults. Brain Struct Funct. 2017 Jan 1;222(1):61-70. [DOI]

20. Lesch KP, Merschdorf U. Impulsivity, aggression, and serotonin: a molecular psychobiological perspective. Behav Sci Law. 2000 Oct;18(5):581-604. [DOI]

21. Nelson R, Chiavegatto $S$. Molecular basis of aggression. Trends Neurosci. 2001;24(12):713-9. [DOI]

22. Bukhari SR, Rashid A, Ali FA. Aggression in male and female university students. Rawal Medical Journal. 2017;42(4):511-3.

23. Hornsveld RH, Zwets AJ, Leenaars EP, Kraaimaat FW, Bout R, Lagro-Janssen TA, Kanters T. Violent female offenders compared with violent male offenders on psychological determinants of aggressive behavior. Int J Offender Ther Comp Criminol. 2018 Feb;62(2):450-67. [DOI]

24. Björkqvist K, Österman K, Lagerspetz KM. Sex differences in covert aggression among adults. Aggress Behav. 1994;20(1):27-33. [DOI]

25. Archer J. Sex differences in physically aggressive acts between heterosexual partners: A metaanalytic review. Aggress Violent Behav. 2002 Jul 1;7(4):313-51. [DOI]

26. Dahal K. Angry relatives attack doctors and hospitals in Nepal. BMJ. 2008;337:1946. [DOI]

27. Ambesh P. Violence against doctors in the Indian subcontinent: A rising bane. Indian Heart J. 2016 Sep 1;68(5):749-50. [DOI]

28. Syed MM. Violence against healthcare professionals: Are we looking for the peaceful truce? Int J Stud Res. 2016 Jan 1;6(1):1. [DOI]

29. Magar A. Violence against doctors in Nepal. J Nepal Med Assoc. 2013 Oct 1;52(192):I-I. [DOI]

30. Ahasan HAMN, Das A. Violence Against Doctors. JOM. 2014 Oct 19;15(2):106-8. [DOI]

31. Gillions A, Cheang R, Duarte R. The effect of mindfulness practice on aggression and violence levels in adults: A systematic review. Aggression and Violent Behavior. 2019 Sep-Oct.48.[DOI] 